\title{
A História Como Pressuposto Filosófico Para a Formação (Política) Docente
}

\author{
José Santos ${ }^{1}$ \\ Marcelo Silva² \\ Letícia Recalde ${ }^{3}$
}

\section{RESUMO}

Este artigo tem como objetivo compreender a matriz teórico-metodológica a Organização do Trabalho Didático, como fundamento para entender a História da Escola Pública Contemporânea. Considera-se que esse pressuposto é importante para formação docente na relação entre educador e educando. A base da análise sobre a discussão partirá da crítica ao modelo manufatureiro, ora negligenciado à formação docente, mas que consideramos fundamental para compreendermos a escola do nosso tempo. Para a realização do trabalho utilizamos a pesquisa qualitativa, com base na análise bibliográfica acerca da discussão sobre a produção da escola moderna. A análise sobre a teoria da história para compreensão do processo da formação docente será questão fundamental para a discussão da organização didática de nosso tempo. Nesta perspectiva será fundamental trazer para a discussão, algo que categoricamente está sendo banalizado nos dias de hoje, o ser humano e sua formação docente. Entendermos o sentido da organização do trabalho didático, a fim propiciarmos um mundo educativo melhor para os trabalhadores da educação básica.

Palavras-chave: (Escola Pública, Organização do Trabalho Didático, Formação de Professores)

ABSTRACT
This article aims to understand the theoretical-methodological matrix the Organization of

\footnotetext{
${ }^{1}$ Graduação em Bacharel em Ciências Econômicas, Mestrado em Educação pela Universidade Metodista de Piracicaba/SP - UNIMEP (1997) e Doutorado em Educação pela Universidade Estadual de Campinas - UNICAMP/ SP (2009). Atualmente é Professor da Graduação nas áreas de Letras, Artes Cênicas e Geografia e; Pós-graduação stricto sensu em Educação Científica e Matemática, Mestrado Profissional, da Universidade Estadual de Mato Grosso do Sul/UEMS. Trabalha com os fundamentos em História e Filosofia da Educação, atuando nas linhas temáticas: Estado - Educação - Políticas Públicas - Sociedade.

${ }^{2}$ Graduação em Filosofia, Mestrado (2003) e Doutorado (2010) em Educação pela Faculdade de Educação da UNICAMP. Atualmente é Professor do Departamento de Educação do Instituto de Ciências Humanas e Sociais da Universidade Federal de Ouro Preto (DEEDU/ICHS/UFOP.

${ }^{3}$ Graduação em Licenciatura Plena em Geografia pela Universidade Estadual de Mato Grosso do Sul (2014), é mestre em Ensino de Ciências pela Universidade Federal de Mato Grosso do Sul (2019). No momento atua como Professora de Geografia na Rede Municipal de Ensino de Campo Grande - MS.
} 
Didactic Work, as a foundation to understand the History of the Contemporary Public School. It is considered that this assumption is important for teacher training in the relationship between educator and student. The basis for the analysis of the discussion will start from the criticism of the manufacturing model, now neglected to teacher training, but which we consider fundamental to understand the school of our time. For the accomplishment of the work we used the qualitative research, based on the bibliographic analysis about the discussion about the production of the modern school. The analysis of the theory of history to understand the process of teacher education will be a fundamental issue for the discussion of the didactic organization of our time. In this perspective, it will be essential to bring to the discussion, something that is categorically being trivialized nowadays, the human being and his teacher training. We understand the meaning of the organization of didactic work, in order to provide a better educational world for basic education workers.

Keyword: (Public School, Organization of Didactic Work, Teacher Education)

\section{Introdução}

A produção desta análise partiu da reflexão proposta sobre o estudo acerca das funções da escola contemporânea com relação à formação docente, no qual entendemos que é deste lugar que nos sentimos desafiados para refletir criticamente numa proposta didática que venha ao encontro dos futuros trabalhadores da educação. Trabalhando com a temática da formação docente da educação básica, nosso referencial teórico partirá da crítica dos pesquisadores da educação que embasam suas análises na discussão da totalidade ${ }^{4}$ e no movimento da disciplina "História e Filosofia da Educação." Nesse sentido, fomos, gradativamente, aperfeiçoando nosso olhar, sobre os fundamentos que alicerçavam o método Ciência da História, através dos grupos de estudos e/ou palestras ou eventos na área da licenciatura. Desnudar a didática na relação com a formação docente, na perspectiva histórica, passou a ser prioridade para pensarmos no processo de produção da existência humana, porque o ser humano vai se modificando, na medida, que vai alterando aquilo que é necessário à sua sobrevivência.

Nesta perspectiva, a discussão sobre a teoria da história será a matriz central desta

\footnotetext{
4 'Totalidade, (...), nada tem a ver com as imprecisas noções de 'todo', de 'contexto social', sistematicamente presentes nas falas dos educadores. Totalidade, no caso, corresponde à forma de sociedade dominante em nosso tempo: a sociedade capitalista. Apreender a totalidade implica, necessariamente, captar as leis que a regem e o movimento que the é imanente. Compreender a educação, nessa perspectiva, supõe, antes de mais nada, o domínio teórico que permite apreender a totalidade em pensamento. Educação, como parte da totalidade social, não nos conduz à totalidade, por mais que as boas intenções dos educadores procurem fazê-lo através de um mergulho nas questões especializadas da área. Aliás, a especialização já é uma limitação ideológica, pois não permite apreender a educação como uma questão social, como uma questão que diz respeito à totalidade. Tratá-la como questão educacional, técnica e especializada, equivale à criação de um impedimento que inviabiliza a captação de seus determinantes". (ALVES, 2006, pp. 10-11).
} 
produção cujo objetivo será o de fundamentar nosso olhar sobre o objeto. Entendermos fundamentalmente que são as condições materiais produzem a realidade e relativizam no plano econômico, que estão na base das relações humanas e, como tal, determinam e condicionam a vida, o trabalho e a educação. Categorias fundamentais para entender a ontologia histórica do ser humano. Isto significa que, trabalho e educação são atividades especificamente humanas, que rigorosamente, segundo Saviani (2007, p.157), "só o ser humano trabalha e educa".

Assim sendo, sistematizaremos este trabalho, refletindo historicamente, como nasceu a concepção da primeira escola, no pensamento de Comenius (1592-1670); trabalhando os pressupostos da matriz teórica de Alves (1998), para compreendermos que a escola pública contemporânea foi fundada no século XVII, "sob a aspiração do modelo manufatureiro". A partir desta consideração que refletiremos sobre a formação docente, dialogando concomitantemente com os aspectos teoricamente negligenciados que acreditamos forjar a nossa crítica a especialização, no movimento da divisão do trabalho. Dado o exposto que, a discussão girará em torno do trabalho técnico didático, como também, para refletirmos a importância da produção de uma nova instituição para a formação de novos trabalhadores da educação e da sociedade.

Portanto, será neste trilhar que tencionamos trazer para a discussão, algo que categoricamente está sendo banalizado nos dias de hoje, o ser humano e sua formação docente. Entendermos o sentido da organização do trabalho didático, a fim propiciarmos um mundo educativo melhor para os nossos trabalhadores do campo e da cidade.

\section{História da Escola Moderna}

$\mathrm{Na}$ análise sobre a escola moderna utilizaremos a reflexão de Alves (2006), onde o autor buscou compreender o rumo das novas demandas oriundas das crises sociais, engendradas dos avanços das tecnologias, em substituição às velhas formas de produção. Para Silva (2017, p. 178):

A concepção da escola pública, laica, focada nos princípios da ciência e produção humanística, em suma os ideais modernos da educação, surgiu no final século XVIII e princípios do século XIX. Sua constituição estrutural e ideológica estava assentada aos ideais do iluminismo, cuja necessidade fora a de propagar os princípios pedagógicos da universalização do ensino. Esse processo partiu do princípio de organização da vida em sociedade, na medida em que as relações: econômicas, de trabalho e da constituição do "homem livre"; passavam por transformações circunstâncias no período em questão, devido a de racionalização da produção e organização da atividade produtiva. Com advento da industrialização, a divisão do trabalho e as mudanças nas relações sociais torna-se fator essencial das relações de produção. Desse modo, surge à demanda por um modelo de cidadão capaz de se adaptar as necessidades da classe que se estabelecia no poder, consolidando seus interesses; a classe burguesa.

Foi nesse movimento, que estava nascendo uma nova instituição, incorporando os novos recursos tecnológicos, tencionando para subverter aquela forma ultrapassada de organiza- 
ção do trabalho didático, sob uma forma contemporânea. "Dessa forma, a escola ajustava-se à nova época, na qual o conhecimento humano se tornara objetivo e o trabalho se objetivara por força da mediação de instrumentos". (ALVES, 1998, p. 9). Pois além de absorver os novos recursos, suas funções também, agora são outras, como a formulação de um novo espaço e de uma arquitetura educacional.

Assim sendo, coube a Comenius o empreiteiro dessa nova concepção, sob o parâmetro das artes, sua organização pensada como uma "oficina de homens". Artes é porque define a consagração do trilhar das manufaturas, o que também indica, o forjar do especialista.

[...]. Aplicando-se ao ofício medieval e à manufatura, o termo arte incorporou dois significados que dificultam a distinção histórica entre eles. Ocorre que a manufatura, depois de ter-se apropriado da base técnica do artesanato, representava a sua superação, pois, através da divisão do trabalho, havia decomposto o todo do ofício medieval em suas operações constitutivas; ao mesmo tempo, especializara os artífices em uma ou poucas dessas operações e, até mesmo, os instrumentos de trabalho, que ganharam formas mais adequadas às operações nas quais eram utilizados [...]. (ALVES, 1998, p. 8).

A superação do artesanato pela manufatura foi a forma assumida pela nova força produtiva, elevando sua produtividade pela divisão do trabalho, elevando a maior produção de mercadoria com o menor tempo e, com o número menor de trabalhadores. Com este cenário que Comenius vê o modelo manufatureiro compondo as necessidades educativas do seu tempo, a escola trabalhando simetricamente à ordem produtiva das manufaturas.

[...] o educador morávio pressupunha uma organização para a atividade de ensino no interior da escola, que a equiparasse à ordem vigente nas manufaturas, onde a divisão do trabalho permitia que diferentes operações, realizadas por trabalhadores distintos, se desenvolvessem de forma rigorosamente controlada, segundo um plano prévio e intencional que as articulava, visando produzir resultados com economia de tempo, de fadiga e de recursos. [...] (ALVES, 1998, p. 8).

Diante da situação anunciada, Comenius conferia no movimento do leito econômico, seus anseios religiosos e políticos consagrados com a proposta da escola para todos, pela via do barateamento dos serviços escolares, como também, a simplificação e a objetivação do trabalho didático, condições importantes para a sua universalização. Importante salientar que seu barateamento passava também pela remuneração do professor, consubstanciado pela mediação do seu instrumento de trabalho. O livro didático.

[...] o manual didático, [...], possibilitaria a queda dos custos da instrução pública. Ao atender esse pré-requisito, necessário à universalização do ensino, esse instrumento do trabalho didático se constituiria, sobretudo, no "ponto central" de uma "questão" que, em última instância, tocava a "remuneração conveniente" dos mestres e os "subsídios" necessários à formação dos "filhos dos mais pobres" (ALVES, 1998, p. 9). 
Assim, a escola ajustava-se à nova época, o sábio artesão dá lugar ao professor manufatureiro ${ }^{5}$, mediado pelos instrumentos que forjariam as condições mínimas, que qualquer ser humano pudesse executar. Essas condições estariam postas nos instrumentos de trabalho docente. O que para Comenius, "tratava-se de simplificar e objetivar o trabalho didático, de tal forma que qualquer homem mediano pudesse ensinar".

Ninguém ignora que a pluralidade dos objetos distrai nossos sentidos. Portanto, haverá grande economia de tempo, em primeiro lugar, se aos alunos só for permitido estudar nos livros didáticos de sua classe [...]. De fato, quanto menos os outros livros ocuparem os olhos tanto mais os didáticos ocuparão os espíritos (COMENIUS, 1997, p. 216).

Dessa forma,

Em segundo lugar, haverá grande economia de tempo se todo o material escolar estiver disponível [...]. Portanto, será muito cômodo já ter prontos, em número suficiente, todos os livros que servirão em cada classe [...]. Assim, todo o tempo que seria perdido a ditar, escrever e traduzir poderá ser dedicado, com muito maior proveito, a explicar, repetir e a fazer tentativas de imitação (COMENIUS, 1997, p. 216).

Tecendo suas considerações, o Saviani (2007) esclareceu que é o trabalho que define a essência humana. Seguindo essa trilha na ontologia humana, entendemos que o ser humano sem a natureza não poderia viver, todavia com o advento da propriedade privada da terra, o do dono da terra, passa a viver e controlar o trabalho alheio. Sedimentando assim a divisão de classe, configurando duas classes sociais:

[...]a classe dos proprietários e a dos não-proprietários. Esse acontecimento é de suma importância na história da humanidade, tendo claros efeitos na própria compreensão ontológica do homem. [...] (SAVIANI, 2007, p. 155).

Como consequência, a educação também resulta da divisão do trabalho. Agora temos uma proposta educativa para a classe dominante, contrapondo a educação para maioria, que continua a coincidir com o processo de trabalho. Na medida em que historicamente esse cenário foi se consolidando, o bispo Morávio anunciava uma nova didática, simplificando e objetivando categoricamente o trabalho docente, coadunando harmonicamente sobre a tecnologia da época manufatureira. O manual didático tornava-se assim, o instrumento necessário ao trabalho docente.

\footnotetext{
${ }^{5}$ Comenius almejou a organização da escola, equivalente à ordem da manufatura, de maneira que a divisão do trabalho possibilitasse diferentes operações, executadas por trabalhadores distintos. A escola se materializou na concepção do grupo escolar e da racionalização do processo pedagógico, cujo desenvolvimento se dava de maneira sistemática e controlada a partir de um plano prévio que se articulava, para obter um resultado com economia de tempo, fadiga e recursos (Silva 2017, p. 178).
} 
Portanto, bastava o professor seguir rigorosamente o receituário imposto pelo instrumento do trabalho didático, fazendo com que qualquer um, com o mínimo de conhecimento pudesse ensinar os conceitos básicos, conferindo assim, funções precisas que se ajustam perfeitamente na relação educativa, fundando uma nova forma histórica de organização do trabalho didático ${ }^{6}$.

\section{Formação de Professores: Uma Necessidade de Nosso Tempo?}

Enfatizar a importância de o educador entender o que é a escola moderna, nos permite anunciar como pressuposto, que a organização manufatureira do trabalho didático evidencia a formação de um professor especialista. Apesar de toda evolução da ciência e consequentemente da tecnologia e da técnica, as políticas de capacitação e formação docente continuam negligenciando tais aspectos para as novas funções de uma nova forma de organização do trabalho didático, para torná-los trabalhadores de fato, sujeitos das transformações da educação e da sociedade. Por essa razão é necessário o entendimento histórico da organização do trabalho didático, no seu procedimento filosófico à formação docente instituído por um modelo de sociedade, que necessariamente passou por um ambiente educativo, por meio da aprendizagem didática, que reitera a produção anacrônica para exercer ofício, não à sua transformação.

Neste sentido, partimos do pressuposto que é fundamental saber que este profissional da educação, além de ter uma formação técnica que lhe permita no momento oportuno lançar mão do conhecimento acadêmico e executá-lo quando sentir necessário. Todavia, não se deve perder de vista que este profissional necessita ter uma formação histórica e filosófica que subsidie a compreensão das relações humanas tão relevantes no ambiente escolar.

A sociedade atual, movida pela informação instantânea, precisa de professores que tenham a capacidade de transmitir o conhecimento aos estudantes de maneira que os façam ter a criticidade necessária para a filtragem daquilo que pode ser verdadeiro ou não. Para tanto, a autonomia deste profissional se faz importante no processo de ensino. Partindo do princípio de que toda forma de ensino, traz uma relação educativa, a qual se realiza em um espaço com uso de instrumentos didáticos, que facilitam o processo ensino/aprendizagem. Assim de acordo com Alves (2005):

1) a relação entre o educador e o educando se realizava sob a forma concreta de relação entre um preceptor e um discípulo;

\footnotetext{
${ }^{6}$ Por ser uma categoria central na discussão ora travada, deve ser explicitada a acepção atribuída à expressão organização do trabalho didático. No entendimento adotado ela incorpora: a) a relação histórica educador-educando; b) a mediação exercida pelos procedimentos do professor, pelos conteúdos didáticos e pelas tecnologias educacionais; e c) e a materialidade espacial e arquitetônica onde tal relação se dá (Alves, 2005, p. 10-11
} 
2) para mediar à relação educativa, o preceptor, quase sempre dotado de uma sólida formação humanística, selecionava, para cada aula e segundo a finalidade correspondente, um pequeno extrato de obra clássica, que, já na condição de conteúdo didático, possibilitava a instauração da lição, ou seja, a leitura inicial da sessão, a primeira operação do trabalho didático que articulava todas as operações subsequentes, tanto as de natureza expositiva quanto as que envolviam discussão;

3) e, quanto ao espaço em que se realizava, o ato educativo poderia dar-se em jardins públicos e privados ou, também, em algum ambiente propício da residência do discípulo ou do preceptor e, mais tarde, na "escola" do monastério ou da catedral. (ALVES, 2005, p. 19).

Se fez necessário recorrer à gênese da relação educativa, para compreendermos como é relevante a categoria "relação educativa", se na Idade Média o processo se dava como descrito por Alves (2005) no momento histórico atual, ela se realiza em similaridade a sua origem. Todavia a educação se realiza em uma escola com instrumentos didáticos mediadores, que são os livros didáticos, embora se faça uso de tecnologias como jogos, materiais didáticos produzidos na instituição ou industrializados, Datashow e computadores.

Algo importante a se considerar é que a didática escolar utilizada no ensino atualmente se fundamenta nos conteúdos prescritos nos Parâmetros Curriculares Nacionais ${ }^{7}$. Por sua vez, são retransmitidos nos currículos de referências das secretarias estaduais e municipais de educação, e se materializam no planejamento do professor tendo como principal instrumento de transmissão o livro didático, que nem sempre atende ao previsto em tais documentos.

No atual governo federal ${ }^{8}$, o que assistimos é a implantação da Base Nacional Comum Curricular/BNCC um instrumento norteador que se tornou a principal referência educacional para o país. Esse documento traz em sua essência a proposta de ensino comum e uma parte diversificada, que atende aos interesses locais. Além disso outro ponto fundamental é o protagonismo do aluno na construção do conhecimento, de tal maneira que essa forma de agir irá levar o estudante a pesquisar e desenvolver projetos que irão proporcionar uma forma de aprendizagem mais sólida.

Essa nova forma de levar o conhecimento trará como consequência mudanças nos currículos e projetos políticos pedagógicos dos cursos de licenciaturas, que deverão estar em conexão com a BNCC, que está sendo aplicada nas instituições de ensino da Educação Básica.

\footnotetext{
${ }^{7}$ Os Parâmetros Curriculares Nacionais/PCN's foram diretrizes elaboradas para orientar a educação brasileira no governo de Fernando Henrique Cardoso, tendo como Ministro da Educação e Desporto - MEC - Paulo Renato Souza nos de 1997 e 1998, em seguida em 1999 foi disposta para o ensino médio.

${ }^{8}$ Base Nacional Comum Curricular/BNCC, documento de caráter normativo, implementado no governo Jair Messias Bolsonaro, tem por objetivo a hegemonia do conhecimento, porém busca atender as especificidades locais, isto se dá no momento de reelaboração dos currículos de referenciais estaduais e municipais, com a participação de professores e coordenadores pedagógicos das respectivas redes de ensino.
} 
O professor de hoje tem de trazer em sua formação inicial a experiência mínima de saber lidar com as ações pedagógicas ${ }^{9}$, alinhadas à compreensão histórica da incorporação da divisão do trabalho, consubstanciada às instâncias superiores a formação especialista de sua instituição escolar. A importância de uma formação que the mostre a origem da escola moderna. Entendemos ser essencial para que este sujeito tenha a dimensão pedagógica e política do seu trabalho, para que ele não seja um mero repetidor de conhecimentos escolares, mas que ele saiba o porquê está realizando tal atividade, seja no processo de alfabetização e letramento, assim como nos conhecimentos das disciplinas das áreas específicas. A formação inicial do professor deve buscar na história e na filosofia as explicações de como a instituição escolar funciona e quais sãos os instrumentos mediadores do trabalho objetivado que o profissional lança mão. No entanto, podemos afirmar que boa parte destes trabalhadores não têm a percepção de que o seu trabalho é pensado por outro, atendendo a interesses que não sejam os seus em ensinar e educar.

Mas, para exercer o trabalho didático, agora sob uma forma contemporânea e as funções sociais reclamadas pelo novo tempo, necessita apoiar-se em soluções originais que mudam todas as referências para a formação de cidadãos e de profissionais especializados e exigem a formulação de novas concepções de espaço educacional e de arquitetura educacional. (ALVES, 2006, p. 16).

A escola pública contemporânea está se modificando em sua forma de funcionar diante da realidade que estamos vivenciando, a era da informação e da tecnologia, estão presentes no cotidiano de alunos e professores. Os recursos tecnológicos que estão à disposição desta geração, estão chegando às instituições de educação, e são instrumentos que permitem melhorar o ensino, mas, não substituem o professor, antes o tem como principal mediador. Diante dos desafios desta época, a formação dos professores em sua fase inicial, tem de estar ajustada à realidade temporal e deve propiciar ao futuro profissional as competências e habilidades para o exercício de seu labor.

Não podemos deixar de evidenciar que a escola da qual estamos falando, que é a pública, atende a maior parte dos estudantes de nosso país. Não que as instituições da rede privada não mereçam atenção, antes pelo contrário atendem a uma demanda da sociedade. Porém a escola pública é a instituição que atende a todos, independentemente de sua condição financeira, e como um órgão do Estado deve ser laica, pública, transparente e gratuita. Como uma instituição secular que vem sendo modificada ao longo da história a escola moderna, deverá ser alterada por aqueles que nela atuam além da sociedade civil. Assim conforme Alves (2008):

Hoje, numa época dominada pela especialização do saber, a edificação de uma nova

\footnotetext{
${ }_{9}^{9}$ Ações Pedagógicas: Envolvem o conhecimento dos métodos, metodologias, conteúdos, currículos, planejamentos, avaliações e didáticas.
} 
didática, necessariamente, não será produto da ação de um intelectual solitário, mas, sim, da atuação coletiva e combinada de muitos especialistas [...] (ALVES, 2008, p. 108).

Face ao exposto, enfatizamos a necessidade de os especialistas da educação fundamentarem a crítica formação do educador para o exercício da cidadania, sobretudo refletindo os limites herdados pela progressiva simplificação do trabalho. Por força da divisão do trabaIho, consolidaram a especialização a formação dos professores nas instituições educacionais superiores, cujo formato é ainda dominante nesses locais. De acordo com Alves (2008):

Pensando na formação do especialista voltado para o exercício do magistério, esse entendimento valoriza os fundamentos da educação e os coloca numa posição central. Um tecnicismo estreito e rudimentar, centrado no "como ensinar", ainda dominante nos cursos de formação e treinamento de professores deve ceder lugar ao próprio domínio do conhecimento. É impossível pensar um especialista em transmissão do conhecimento à margem desse domínio. As formas de transmissão tendem a subordinarem-se às especificidades das formas de produção do conhecimento, correspondentes a cada área do saber. (p. 109).

Portanto, para se ter um novo profissional é preciso ter uma nova didática de ensino em sua formação inicial. De acordo com Alves (2008) é preciso romper com o tecnicismo ainda imperativo em nossa época, e propor uma forma de ensino que vise dar ao futuro professor o domínio do conhecimento e não o limitando a atividades parciais como as especializações tecnicistas impõem aos profissionais do magistério.

No entanto, o professor deve sempre buscar as suas bases históricas e filosóficas para entender a sociedade que se metamorfoseia ao longo da história em um movimento contínuo. Mas, sobretudo o profissional precisa ter em suas mãos o processo de ensino de maneira subjetiva, para romper com a especialização imposta pela educação manufatureira.

O processo de formação dos professores, em nossos dias, só faz reiterar essa dissonância. Por continuarem reproduzindo a organização manufatureira do trabalho didático e, ao mesmo tempo, por induzirem à crença em uma autonomia do docente na direção do processo de formação de crianças e jovens, os cursos de formação e treinamento de professores produzem profissionais que realizam diuturnamente, também eles, uma prática que reforça a dissonância. Esses cursos são fundamentais, portanto, para manter a escola manufatureira tal como se encontra e, ao mesmo tempo, para cultivar o mito do professor que impõe direção autônoma ao trabalho didático. Em resumo, por aferrarem a escola ao passado e por resistirem à mudança, esses cursos de formação e treinamento de professores são politicamente reacionários (ALVES, 2008, p. 105).

A aparência de que o professor é um sujeito autônomo no processo de ensino aos seus alunos, não condiz com a sua essência manufatureira e de um trabalho objetivado. Ainda segundo Alves (2008) os cursos de formação continuada e atualização pedagógica fazem 
perpetuar no professor um profissional especialista sem ter o domínio do trabalho pedagógico de maneira abrangente. De acordo com Alves (2005, p. 70-71):

Em síntese, a persistência da organização do trabalho didático, concebida por Comenius, confere à atividade dos professores características extemporâneas, pois típicas da organização técnica do trabalho manufatureiro, dominante na época em que viveu o bispo morávio. Entre os preços que o homem paga por esse anacronismo, hoje, um dos mais sérios é a impossibilidade de ascender, por meio da educação escolar, ao conhecimento culturalmente significativo. A transmissão do conhecimento, na escola, identificou-se, de fato, com a sua vulgarização."

A bem da verdade, a proposta comeniana respondeu a um momento histórico do seu tempo, mobilizando os recursos pensados e produzidos pelo homem de sua época, como o relógio confiável, a reprodução de trabalhos impressos e, sobretudo a divisão do trabalho. Importante para a nossa compreensão que o tempo é outro, marcado por novas necessidades sociais, como as questões étnico raciais, gêneros, LGBT e direitos humanos, reforçam em nossa crítica a dotação dos novos recursos tecnológicos, como forma de entendermos que o processo da existência humana é um processo social. Assim, de acordo com Alves (2008, p. 106-107):

[...]. Isto é, didática constitui uma proposta de educação para a sociedade; visa atender necessidades sociais e mobiliza, para a sua consecução, os recursos mais avançados produzidos pela humanidade em seu tempo. Se a proposta de Comenius respondeu a uma necessidade social de sua época, mobilizando para superá-lo os recursos mais avançados então produzidos pelo homem, hoje o tempo é outro, marcado por novas necessidades sociais e dotado de recursos tecnológicos mais pertinentes à superação dessas mesmas necessidades. Trata-se, então, repetindo, de construir uma nova didática ajustada ao nosso tempo.

O nosso desafio na formação docente com relação à didática, ainda se dá pelo exercício histórico da compreensão da história da escola moderna, sobretudo no entendimento do como funciona a nossa sociedade capitalista. Nesta trilha que acreditamos que somente com a compreensão de como funciona a sociedade do seu tempo, é o que permite o trabalhador da educação aprender os limites estruturais a sua classe social, que lhe abrem lutar por uma nova demanda mais substantiva, como afirma ALVES (2005, p. 74) - "que emana de uma nova concepção de educação do trabalhador".

\section{Considerações Finais}

Podemos concluir que a construção de uma nova didática não acontecera do mesmo molde daquela concebida por Comenius, o bispo morávio era sábio, e como tal, facultava o domínio dos problemas sociais de sua época. Na relação histórica entre o universal e o 
singular, a nossa singularidade é dominada pela especialização do saber, notadamente tal construção não se consolidara por uma ação solidária, mas com certeza por uma participação coletiva que coloquem a Ciência da História, no centro da revalorização dos fundamentos da educação.

Logo, não basta colocar os recursos tecnológicos de nossa época, e acreditar que tais instrumentos técnicos, centrados no como ensinar, cederam o lugar à apropriação do conhecimento, nas formas de transmissão a margem do domínio elaboradas por especialistas da área.

Devemos considerar também, que historicamente a nossa singularidade educação brasileira, retrata as contradições da reforma e contrarreforma no campo das relações sociais. Ambas derivadas do modelo produtivo colonial, onde categoricamente o trabalho, revelam as marcas culturais históricas do elitismo e a excludência. Importante fazer tal ressalva, para entendermos que para democratizar o conhecimento, torna-se imperativo o acesso de todos a educação e, sobretudo ao conhecimento e a apropriação das tecnologias, para o exercício didático de um conhecimento culturalmente significativo, como livros e obras clássicas, vídeos, filmes, internet etc. - "só não pode fazer concessões aos instrumentos que realizam a exclusão deste” - como afirma ALVES (1998, p. 17).

Neste itinerário, ALVES (2005, p. 76), é preciso “[...] Tornar-se imperativa a produção de uma nova organização do trabalho didático cujo fundamento deve ser buscado nos recursos tecnológicos contemporâneos". - Com esse objetivo que podemos olhar a História para compreendermos que:

É o processo da produção da existência humana porque a cada nova interação reflete uma natureza modificada, pois nela se incorporam criações antes inexistente, e reflete, também, um homem modificado, pois suas necessidades, condições caminhos para satisfazê-las são outros que foram sendo construídos pelo próprio homem. [...] (ANDERY et al., 2003, pp. 10-11).

É nesse sentido que devemos disseminar um conhecimento culturalmente significativo, para tanto, faz-se importante ressaltar que:

[...]. É nesse processo que o homem adquire consciência de que está transformando a natureza para adaptá-la a suas necessidades, característica que vai diferenciá-lo: a ação humana, ao contrário de outros animais, é intencional e planejada, em outras palavras, o homem sabe que sabe (ANDERY et al.,2003, p. 11).

Logo, é necessário que se reafirme, o nosso compromisso da construção social de uma nova forma de organização do trabalho didático, comprometida com a necessidade de universalizar a cultura, para efeito de criarmos novas demandas sociais, para que possam ser tão fundamentais, quanto as chamadas situações básicas à nossa sobrevivência, como decorrência lutarmos pelas nossas conquistas históricas, dentre elas a Democracia, a inclusão 
dos excluídos de modo geral, a preservação do meio ambiente, pela a paz, pelo o amor justiça social e para resistirmos e construirmos a nossa própria história da educação brasileira.

\section{Referências Bibliográficas}

ALVES, Gilberto Luiz. O trabalho didático na escola moderna: formas históricas. Campinas, SP: Autores Associados, 2005.

ALVES, Gilberto Luiz. A produção da escola pública contemporânea. $4^{a}$ ed. Campinas, SP: Autores Associados, 2006.

ALVES, Gilberto Luiz. Formação de professores: uma necessidade de nosso tempo. Revista HISTEDBR on-line, Campinas, n.31, pp. 102-112 Set. 2008.

ALVES, Gilberto Luiz. Uma nova instituição educacional para o nosso tempo. Educere Et Educare Revista de Educação. Vol. I n. 1 jan. /jun. 2006.

ALVES, Gilberto Luiz. Nasce uma nova Instituição Educacional. Intermeio: revista do Mestrado em Educação, Campo Grande, MS, 4(8): 6-17, 1998.

ANDERY, Maria Amália Pie Abid, et al. Para compreender a ciência: uma perspectiva histórica. $12^{\mathrm{a}}$ ed. Rio de Janeiro: Garamond; São Paulo: EDUC, 2003.

COMENIUS, Iohannis Amós. Didática Magna, 1654. Fundação Calouste Gubbenkian, 2001.

SAVIANI, Dermeval. Trabalho e Educação: fundamentos Ontológicos e Históricos. Universidade Estadual de Campinas, Faculdade de Educação. Revista Brasileira de Educação. V.12 n. 34 jan./abr. 2007.

SAVIANI, Dermeval \& DUARTE, Newton (Orgs.). Pedagogia histórico-crítica e luta de classes na educação escolar. Campinas/SP. Autores Associados, 2012.

SILVA, Marcelo D. da. Epistemologia e Educação étnico-racial: análise dos manuais didáticos do Ensino Fundamental de Mariana-MG. REVISTA PEDAGÓGICA | V.19, N.40, JAN./ABR. 2017.

SILVA, Marcelo D. da e QUIRINO, Kátia Maria dos S. A difusão da cultura negra na formação de professores da EJA: uma análise sobre as questões étnico-raciais nas escolas de Mariana-MG. Revista Brasileira de Pesquisa Sobre Formação de Professores v.12 n.23, p 153-166 jan/abr, 2020. 